\title{
ATTITUDES TOWARD EARTHEN ARCHITECTURE: THE CASE OF COMPRESSED AND STABILIZED EARTH BLOCK ARCHITECTURE IN AUROVILLE, INDIA
}

\author{
NOURREDINE KEBAILI \& KEHILA YOUCEF \\ Laboratoire Architecture et Environnement, Ecole Polytechnique d'Architecture et d'Urbanisme, Algérie
}

\begin{abstract}
This study aims at analyzing the presumed negative attitudes toward earthen architecture as a component of a statistical analysis that attempts to gather information to understand what causes it. A survey was conducted in a city experiment consisting of the revalorization of an earthen-based building technique called compressed and stabilized earth blocks (CSEB). This experiment has been conducted by the Auroville Earth Institute team (AVEI) for over 25 years and seeks to inform individuals of the usefulness of this environmental friendly building material. It proposes CSEB products as an alternative to conventional materials. In this context AVEI promotes dwellings constructed entirely with CSEB. For the primary conclusion, the negative side of the attitudes toward earthen architecture is too complex to grasp and it is explained by the relationship between the different attitudes toward building materials and buildings. Comparisons with attitudes toward fired brick architecture result in indicators that could benefit CSEB revalorization projects. These results lead to research regarding attitudes toward building materials and their wide-ranging uses.
\end{abstract}

Keywords: attitudes toward earthen architecture. attitudes toward homes. attitudes toward building materials.

\section{INTRODUCTION}

This research aligns with architectural psychology concepts proposed by environmentalists [1]. It focuses on earthen architecture, which encompasses all buildings constructed with products manufactured using material that constitutes natural soil, also known as earth [2]. The relevant technique analyzed in this article is compressed and stabilized earth block (CSEB), which involves adding a stabilizer and compressing appropriate soil to shape building blocks. Earthen architecture is distinguished by the building material and differs from architecture using other building materials. One of the interests of this field of study lies in CSEB's ecological and sustainable quality [3]. This aspect motivates numerous organizations around the world to seek its revalorization.

In 2010, the World Monument Fund (WMF), in collaboration with the UNESCO World Heritage Centre and the Governorate of Luxor, launched a conservation project at the New Gourna village in Egypt [4]. New Gourna is an earthen village developed by the prominent architect Hassan Fathy and illustrates attempts to revalorize earthen architecture in the twentieth century. The WMF report illustrated the ongoing plight of this exemplary project; inhabitants clearly demonstrated their negative attitudes toward the building material and earthen architecture proposed by Hassan Fathy [5]. For proponents of the New Gourna earthen architecture, home architecture is the result of the use of adobe brick [6]. The new Gourna village illustrates the risk of negative attitudes that threaten current attempts to revalorize earth-based building materials and ecological architecture. Positive attitudes guarantee the sustainability of architecture and consequently the sustainability of the use of earth-based building materials.

For more than 25 years, the Auroville Earth Institute (AVEI) has worked for the revalorization of CSEB in Auroville and worldwide [7]. This study focuses on data collected 
in Auroville and attempts to assess attitudes toward CSEB architecture and CSEB building materials. The primary objective is to develop methods of assessing earthen architecture revalorization projects to innovate methods of persuasion that are capable of encouraging the use of this environmentally friendly material in the building industry.

\section{OBJECTIVES OF THE RESEARCH}

This study enquires into the reasons of the negative attitudes of inhabitants using statistical means. This task is accomplished by linking attitudes toward homes with those toward building materials. To achieve this goal, we analyze issues related to; first, the characteristics of attitudes toward homes and attitudes toward building materials and second, to the relationships between these two above-mentioned attitudes.

For proponents of CSEB architecture the building material is the basis of ecological architecture. Regarding the necessity of studying building material attitude, this investigation focuses on homes to afford the opportunity of analyzing this aspect. We believe that if individuals do not talk much about architecture, as emphasized in an address by the director of Aga Khan Architecture Price, Farrokh Derakhshani in a ceremony celebrated at the Ismaili Centre in Lisbon in 2013, then they might talk less about building materials.

Earthen architecture revalorization projects include housing and community facilities. This study focuses solely on housing. This does not mean that this research excludes community facilities, but for this case, it was easier to proceed with attitudes toward homes to determine attitudes toward the building material. We intend to include an analysis of community facilities in the future.

\section{METHOD OF RESEARCH}

This quantitative analysis is correlational because it seeks to observe attitudes toward both homes and building materials and to establish relationships between these attitudes [8]. A semantic differential was used for the survey form to analyze the attitudes of the participants. The AVEI team used eight scales from the list of adjectival scales provided by Osgood and Tannenbaum in their well-known book, The measurement of meaning [9]. Four scales were added regarding the key themes of ecology, satisfaction, cost effectiveness and the symbolic opposition of poverty and wealth. We used twelve scales to preserve the functionality of the form and encourage participation by residents. Each scale consisted of seven steps that ranged from step ' 1 ' for extremely unfavorable attitude to step ' 7 ' for extremely favorable attitude. Step '4' represented a neutral attitude. The survey measured attitudes toward three concepts that included the resident's home, fired brick and CSEB.

For this study, attitude refers to the valence, which is the primary studied object of research regarding attitudes and may be the most studied aspect of all. The valence of an attitude is the degree of favorability toward a given object of attitude. In other studies, in English, this term is often referred to as magnitude [10]. Valence may be positive, negative or neutral and is the evaluative dimension of attitude measured by the classical scales utilized by Bogardus, Thurstone, Likert, Guttman and Osgood [10].

Both descriptive and inferential statistical methods were utilized to summarize and analyze the data collected by this survey [8]. The score for each concept was calculated as the average of the twelve scales. The following seven favorability classes were used for this study:

1. Degrees between 1-1.5 form the "Extremely unfavorable" class.

2. Degrees between 1.5-2.625 form the "Quite unfavorable" class.

3. Degrees between $2.625-3.75$ form the "Slightly unfavorable" class. 
4. Degrees between 3.75-4.25 are of the "Neutral" class.

5. Degrees between 4.25-5.375 form the "Slightly favorable" class.

6. Degrees between 5.375-6.5 form the "Quite favorable" class and.

7. Degrees between 6.5-7 form the "Extremely favorable" class.

We often use the term degree of favorability of valence of attitude (DFVA) when referring to these classes. Version 20 of SPSS software was used for data analysis. The presentation of data and the writing of the results are in line with the guidelines of the American Psychology Association [8].

\section{HYPOTHESES OF THE RESEARCH}

The primary hypothesis stems from the assumption of a negative attitude toward earthen architecture. The attitudes toward CSEB homes may appear on the differential scale of the survey form; therefore, the first hypothesis may be verified. If the attitude is negative, then the average of collected attitudes will range between 1 and 3.75; this is in the range of the negative attitude classes, specifically the extremely, quite and slightly unfavorable classes. Conversely, average attitudes are in the range of the neutral or favorable attitude classes, specifically the extremely, quite and slightly favorable classes. Negative attitudes toward CSEB homes are apparent in the average scores of the semantic differential.

The second hypothesis is proposed in the case that differential scales fail to detect negativity in the attitudes toward CSEB homes. This hypothesis seeks to compare attitudes toward CSEB homes with attitudes toward fired brick homes and assumes that this latter is rated better than the former. It is expected that, on average, fired brick homes will rate higher than CSEB homes on the differential scale of the survey form. If this occurs, then negative attitudes toward CSEB homes will remain in the rating classification.

The third hypothesis relates to attitudes toward building materials, particularly CSEB and fired brick. This hypothesis is derived from the definition of earthen architecture and assumes that the attitudes toward CSEB buildings are influenced by attitudes toward CSEB. The means of verifying this hypothesis is the equivalence of attitudes. Correlation confirms and measures the degree of equivalence and also verifies the positive or negative direction of influences between attitudes.

\section{THE CASE STUDY}

To conduct this research, we selected Auroville, an international township in southern India where a noteworthy revalorization project of earthen architecture is taking place due to the world-renowned team of AVEI [7].

Stabilization of CSEB is often achieved by adding a certain percentage of cement or lime to the mixture of soil sand and water. This mixture is compressed into a mold to take various forms and sizes depending on the intended use. Compression is achieved using manual or mechanical machines. The compressed product is used after it dries. CSEB products are advantageous because of the possibility of onsite production and, in particular, their ecological characteristics. The embodied energy of a CSEB block varies from $2.412 \mathrm{MJ} / \mathrm{unit}$ to $4.599 \mathrm{MJ} / \mathrm{unit}$, and the carbon emissions vary from $41.874 \mathrm{KgCO}_{2} / \mathrm{m} 3$ to $79.837 \mathrm{KgCO}_{2} / \mathrm{m} 3$. To understand the advantage of using these figures, we use the comparison of embodied energy of a fired brick block, which varies from $3.457 \mathrm{MJ} / \mathrm{unit}$ to $10.006 \mathrm{MJ} /$ unit, and the carbon emissions vary from $202.255 \mathrm{KgCO}_{2} / \mathrm{m} 3$ to $642.866 \mathrm{KgCO}_{2} / \mathrm{m} 3$. These figures were calculated in the Indian context [11]. Therefore, we note that CSEB uses less than half of the embodied energy and reduces at least one-eighth of the carbon emissions when compared to the use of fired brick. 


\section{CONDUCT OF THE INVESTIGATION}

With assistance from the AVEI team, a campaign was launched that invited the Auroville population to participate in the survey. Posters were displayed in numerous public locations throughout the city. In addition, announcements were published in the local weekly newspaper and its website and on the AVEI website where individuals were able to download the form and submit it by email. Three investigators were mobilized for the distribution and collection of completed forms. These investigators traveled public streets and asked individuals to participate. Participants were asked to do one of the following tasks:

1. To take a form to complete and return immediately or submit to AVEI at a later point in time.

2. To provide their email addresses to receive a digital form to complete and submit via email.

3. To access the website to complete and submit the completed forms by email to AVEI.

A progress report was published weekly in the local newspaper to encourage participation. Data was collected primarily during June, July and August 2014.

More than 7,000 individuals reside in Auroville, and a total of 347 units responded to our survey. 35 units resided in CSEB homes at a rate of $10.1 \%$. A total of 237 units resided in fired brick homes, at a rate of $68.3 \%$. 65 units resided in homes constructed using other building materials, at a rate of $18.7 \%$, and 10 units did not provide an answer regarding the type of building materials, at a rate of $2.9 \%$. A Chi-squared test demonstrated that the obtained rates were significant, $\chi^{2}(3)=364.458$ and $\mathrm{p}=0.000$. This result may be interpreted to reflect extensive use of fired brick and restricted use of CSEB in Auroville.

This result is somewhat disturbing considering many years of effort. The New Gourna situation discussed in the introduction leaves proponents of CSEB architecture puzzled, since it could be the case of Auroville. Seeking a method to conduct a situation assessment implies that it is essential to closely follow the evolution of attitudes and encourage the use of this environmentally friendly material. The following paragraphs provide the descriptive results and the results of statistical testing. We discuss the overall results in the conclusion.

\section{ATTITUDES TOWARD HOMES}

The overall attitude toward homes, regardless of the building material, is presented in this paragraph. Attitudes toward CSEB homes will be presented later for comparison. Fig. 1 provides the distribution of DFVA toward the homes of all units.

We note that the sample had an average of $M=4.78$; therefore, on average, the attitudes toward homes were slightly favorable. The standard deviation was $\sigma=1.16$. This is relatively small when compared to the average of 4.78 because the standard deviation value is nearly a quarter of the average. The registered values of DFVA toward homes are relatively grouped around the average, which indicates a good representation of the group.

We note the absence of good symmetry of the bars. The observed distribution approaches the normal distribution. It is negatively skewed and rather flattened platykurtic with a negative kurtosis.

To generalize the results to the entire population, we compared the calculated mean first with the upper limit of the neutral class of 4.25 and then with the value of 5.375 , which is the lower limit value of the quite favorable class. These two values limit the slightly favorable 


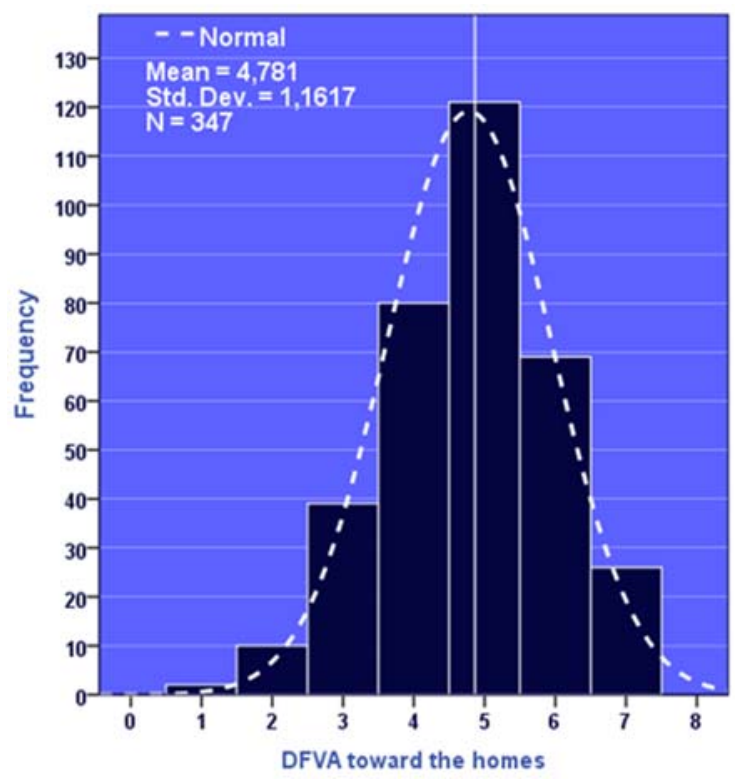

Figure 1: Histogram of attitudes toward the homes.

class to which the value of 4.78 belongs. We report the test results as follows:

- Compared to 4.25: On average, the attitudes of the participants were significantly not neutral regarding homes $(\mathrm{M}=4.78, \mathrm{SE}=0.06)$, and the difference between the recorded mean and the upper limit of the neutral class $(0.53,95 \%$ CI $[0.41,0.65])$ was significant $(\mathrm{t}(346)=8.51, \mathrm{p}=0.000)$; however, it represented an effect below the average $(\mathrm{r}=0.42)$.

- Compared to 5.375: On average, the attitudes of the participants toward homes were significantly below the quite favorable class $(\mathrm{M}=4.78, \mathrm{SE}=0.06)$, the difference between the recorded mean and the lower limit of the quite favorable class $(-0.59,95 \%$ CI $[-0.72,-0.47])$ was significant $(\mathrm{t}(346)=-9.53, \mathrm{p}=0.000)$; however, it represented an effect below the average $(\mathrm{r}=0.46)$.

To clarify, attitudes toward homes were significantly slightly favorable; this result is representative of the population in Auroville and is not limited to the sample. Next, we will determine the particular characteristics of attitudes toward CSEB homes and will compare them to attitudes toward fired brick homes.

\section{ATTITUDES TOWARD CSEB HOMES}

In the following paragraph, we present the attitudes toward CSEB homes. As before, we will first analyze these attitudes by including a brief description. Then, we will compare this definition to attitudes toward CSEB and will study the relationship between these two attitudes. Recall that the sample size is $n=35$ because only 35 units residing in CSEB houses participated in the survey. We will compare these two attitudes of the participants.

The histogram on the left in Fig. 2 provides the distribution of DFVA toward CSEB homes. On average, attitudes were slightly favorable, $\mathrm{M}=4.88$. The standard deviation was 
$\sigma=1.20$ and was relatively small when compared to a mean of 4.88 because the standard deviation value is nearly a quarter of the mean. The values of DFVA toward CSEB homes are relatively clustered around the mean which is a good representation of the group of units inhabiting CSEB houses. The histogram is negatively skewed because the largest frequencies are on the right side of the mean with a gradual decline to the right. It is rather platykurtic with a negative kurtosis.

To generalize these results to all residents living in CSEB homes in Auroville, we compared first with the upper limit of the neutral class of 4.25 and then with the value of 5.375 , which is the lower limit value of the quite favorable class. These two values limit the slightly favorable class to which the value of 4.88 belongs. The Wilcoxon test was used. The results are as follows:

- Compared to 4.25: The attitudes toward CSEB homes of participants inhabiting CSEB homes were significantly different from the upper limit of the neutral class $(\mathrm{Mdn}=5.29, \mathrm{z}=2.802, \mathrm{p}=0.005, \mathrm{r}=0.47)$.

- Compared to 5.375: The attitudes toward CSEB homes of participants inhabiting CSEB homes were not significantly different from the lower limit of the quite favorable class $(\mathrm{Mdn}=5.29, \mathrm{z}=-1.934, \mathrm{p}=0.053, \mathrm{r}=-0.33)$.

This latter result led to a subsequent review of the data using the lower limit of the extremely favorable class value of 6.50 . We obtained the following results: The attitudes toward CSEB homes of the participants inhabiting CSEB homes were significantly different from the lower limit of the extremely favorable class $(\mathrm{Mdn}=5.29, \mathrm{z}=-5.015, \mathrm{p}=0.000$, $\mathrm{r}=-0.85)$.

The attitudes toward CSEB homes ranged from slightly favorable to quite favorable. The recorded median of 5.29 , BCa $95 \%$ CI $(4.29,5.43)$, was representative of the population living in CSEB homes in Auroville.

The question that arises now is; are attitudes toward CSEB homes different from attitudes toward homes built with other building materials? To answer this question, the Kruskal-Wallis test was used to compare the attitudes of the three groups; participants residing in CSEB homes, participants residing in fired brick homes and participants residing in homes built with other building materials. Following is the result; there were no significant differences between attitudes toward CSEB homes, attitudes toward fired brick homes and attitudes toward homes built with other building materials $(H(2)=2.090, \mathrm{p}=0.352)$.

No difference existed between the attitudes toward CSEB homes and the common attitudes toward homes in Auroville. We compared the distribution of the DFVA toward CSEB homes with the DFVA toward CSEB. The histogram on the right in Fig. 2 provides the DFVA toward CSEB. This result demonstrated that the means and standard deviations were nearly identical. We conducted the Wilcoxon test for paired samples to determine if this difference was significant. The result is as follows; the attitudes toward CSEB ( $\mathrm{Mdn}=4.83$ ) were not significantly different from attitudes toward CSEB homes ( $M d n=5.29, z=-0.365$, $\mathrm{p}=0.715, \mathrm{r}=-0.06$ ).

Therefore, attitudes toward CSEB homes were statistically equivalent to those toward CSEB, which verifies the third hypothesis. Attitudes toward CSEB homes are displacements of the attitudes toward CSEB; however, we are unable to provide the extent of the equivalence.

We sought to ascertain if the equivalence between attitudes toward the building material and attitudes toward homes built with an identical material existed in the case of attitudes toward fired brick. This will be discussed in the following paragraph. 


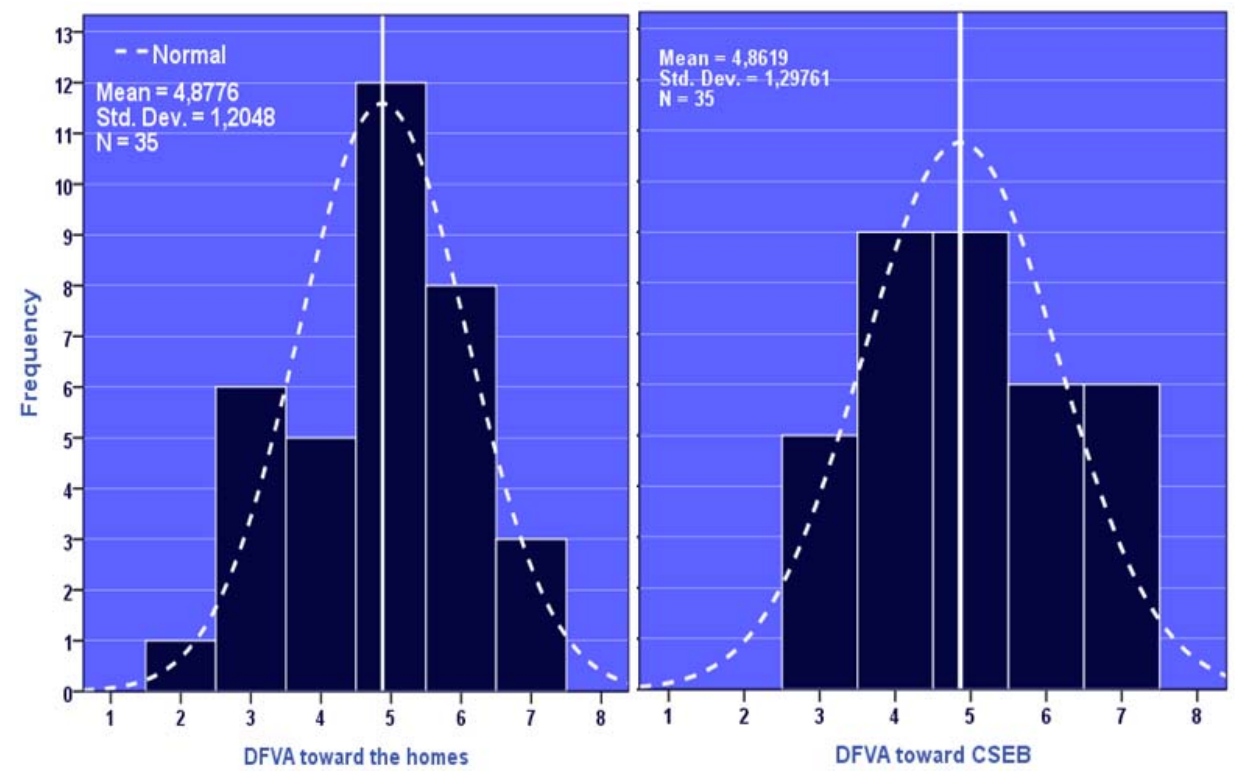

Figure 2: Histograms of DFVA toward CSEB homes and toward CSEB.

\section{COMPARISON TO ATTITUDES TOWARD FIRED BRICK HOMES}

Comparison allows the extraction of certain indicators that help to assess attitudes toward CSEB homes and revalorization projects. For this case, n equals 237. Histogram on the left in Fig. 3 provides the distribution of DFVA toward fired brick homes and indicates that on average, participants' attitudes were slightly favorable $(\mathrm{M}=4.75)$, and the standard deviation was $\sigma=1.16$. This is relatively small when compared to a mean of 4.75 because it makes up nearly a quarter of the mean. The values of the DFVA toward fired brick homes are relatively grouped around the mean, which is a good representation of survey participants living in fired brick homes. The data are negatively skewed and rather platykurtic with a negative kurtosis.

To generalize this result to all fired brick home residents in Auroville, we compared the mean with the two values that limit the slightly favorable class, to which the value of 4.75 belongs. The test results are as follows:

- Compared to 4.25: On average, the participants' attitudes toward fired brick homes were significantly non-neutral $(\mathrm{M}=4.75, \mathrm{SE}=0.08)$, and the difference between the recorded mean and the upper limit of the neutral class $(0.50,95 \%$ CI $[0.36,0.65])$ was significant $(\mathrm{t}(236)=6.68, \mathrm{p}=0.000)$; however, it had an effect between large and medium $(\mathrm{r}=0.4)$.

- Compared to 5.375: On average, the participants' attitudes toward fired brick homes were significantly below the quite favorable class $(\mathrm{M}=4.75, \mathrm{SE}=0.08)$, and the difference between the recorded mean and the lower limit of the quite favorable class $(-0.62,95 \%$ CI $[-0.77,-0.47])$ was significant (t $(236)=-8.23, \mathrm{p}=0.000)$; however, it had an effect beneath the large $(r=0.47)$.

Attitudes toward fired brick homes were significantly slightly favorable, and this result is representative of the population living in fired brick homes in Auroville. Recall that the 
second hypothesis implies that the average score of fired brick home attitudes was higher than the score of CSEB home attitudes. However, attitudes toward CSEB homes ranged between the slightly favorable class and the quite favorable class $(\mathrm{M}=4.88)$, which was slightly higher than attitudes toward fired brick homes $(M=4.75)$. We will verify the significance of this difference. The result of the Mann-Whitney comparison of two independent samples test is as follows; on average, the attitudes toward CSEB homes of participants inhabiting CSEB homes $(n=35$, mean rank=146.31) were not significantly different from the attitudes toward fired brick homes of participants inhabiting fired brick homes $(\mathrm{n}=237$, mean rank=135.05, $\mathrm{U}=3804.000, \mathrm{z}=-0.791, \mathrm{p}=0.429, \mathrm{r}=0.05)$.

Thus, attitudes toward homes were statistically identical for fired brick and CSEB houses. This result confirms prior evidence but tested the second hypothesis of the research, which was invalidated because attitudes toward CSEB homes were most likely neither inferior nor superior to attitudes toward fired brick homes. Now, we will analyze if attitudes toward fired brick are equivalent to attitudes toward fired brick homes. We compare attitudes toward fired brick homes with attitudes toward fired brick. Histogram on the right in Fig. 3 represents the DFVA toward fired brick. We note that the means are different but the standard deviations are nearly identical. We proceed with the t-test to determine whether they may be considered identical or not. The result is as follows; on average, the attitudes toward fired brick ( $M=4.49$, $\mathrm{SE}=0.08)$ were significantly lower than attitudes toward fired brick homes $(\mathrm{M}=4.75$, $\mathrm{ES}=0.08)$, and the difference $(-0.27,95 \% \mathrm{CI}[-0.44,-0.09])$ was significant $(\mathrm{t}(236)=-3.049$, $\mathrm{p}=0.003)$, representing a negative effect that ranged between low and medium $\mathrm{d}=-0.23$.

Attitudes toward fired brick homes were statistically higher than attitudes toward fired bricks even though they belong to the same class of slightly favorable attitudes. Attitudes toward fired brick homes and attitudes toward CSEB homes remained statistically equivalent; however, attitudes toward CSEB homes were statistically equivalent to attitudes toward CSEB.

The equivalence between the two attitudes is interpreted as a displacement of attitudes toward CSEB to that of CSEB homes. This is not the case of attitudes toward fired brick homes. The equivalence relationship is notable because it allows a new hypothesis that links the equivalence relationship and the broad or limited use of building materials. This new research field could establish the limits of traditional uses of building materials and may define which building materials need revalorization projects and those that may increase without the help of revalorization programs. This new research field examines attitudes toward different building materials and will investigate the connection between the broad or limited use of a building material and the equivalence of attitudes toward buildings and on building materials.

\section{THE RELATIONSHIP BETWEEN ATTITUDES TOWARD CSEB HOMES AND ATTITUDES TOWARD CSEB}

We note that equivalence existed between attitudes toward CSEB homes and attitudes toward CSEB. We now quantify this equivalence link. It is acknowledged that the correlation coefficient represents the relationship between two variables [8]. We assume then that this coefficient quantifies this equivalence. It will demonstrate the amount of common variability or the bonding strength and its positive or negative direction between attitudes toward building materials and attitudes toward homes [8].

Naturally, we assume that the DFVA toward CSEB and the DFVA toward CSEB homes are highly correlated because the building material is used to construct the residence. We used the bivariate Pearson correlation test between the two variables; DFVA toward CSEB 


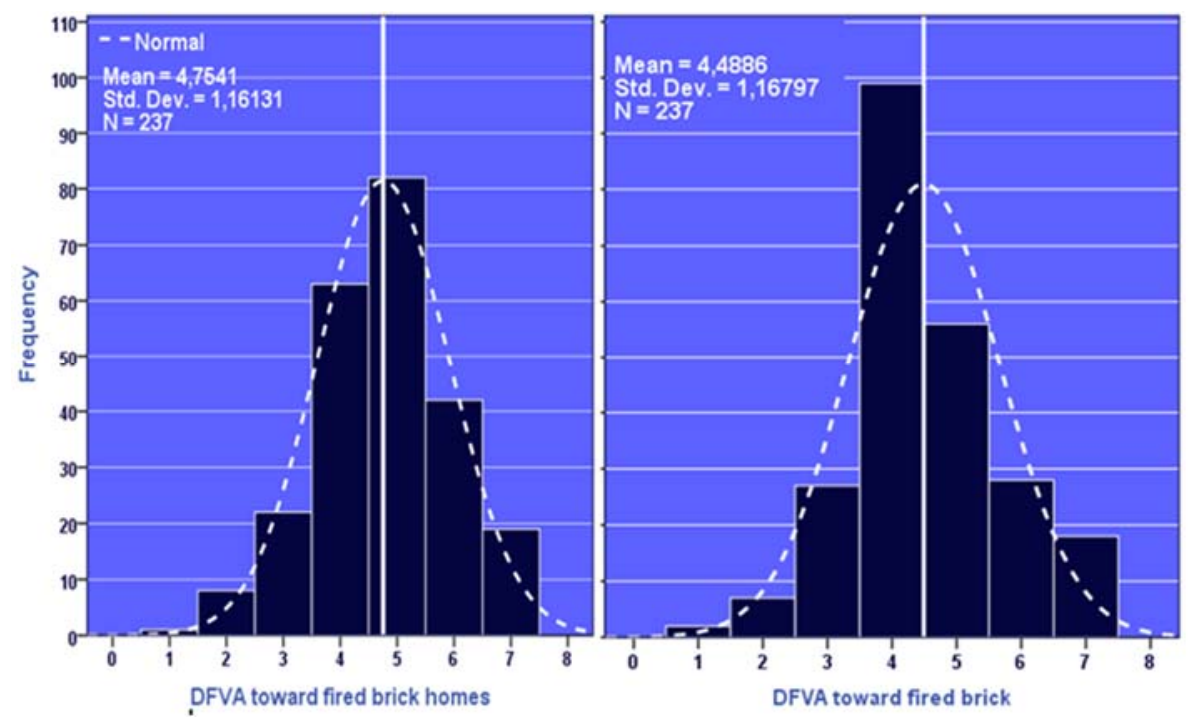

Figure 3: Histograms of DFVA toward fired brick homes and toward fired brick.

homes and the DFVA toward CSEB which provided the following result: Attitudes toward CSEB homes were significantly correlated to attitudes toward CSEB $(r=0.646, p=0.000)$.

We note the test resulted in a positive Pearson bivariate correlation coefficient ' $r$ ', which indicated that attitudes toward CSEB homes and CSEB were positively and strongly related. The determination coefficient R2 (R2=r2) indicated that these two attitudes shared $41.73 \%$ of their variability. To clarify this result, we conducted a test with a referral correlation coefficient between attitudes toward both fired brick and fired brick homes. We conducted the bivariate Pearson correlation test between two variables with bootstrapping; the DFVA toward fired brick homes and the DFVA toward fired brick, which provided the following result; attitudes toward fired brick homes were significantly correlated with attitudes toward fired bricks ( $\mathrm{r}=0,338$, BCa 95\% CI [0.206, 0.452], $\mathrm{p}=0.000)$.

We note that the Pearson bivariate correlation coefficient was also positive ' $r$ ', but this relationship was medium. The difference between these two Pearson correlation coefficients -0.308 was significant $(\mathrm{z}=-2.21, \mathrm{p}=0.027)$. This result indicated a genuine difference between these two relationships.

The coefficient of determination R2 between attitudes toward both fired brick homes and fired bricks demonstrated that these two attitudes shared only $11.42 \%$ of their variability. This was nearly $1 / 4$ of what was shared between attitudes toward CSEB homes and toward CSEB; the latter is large as a common variability compared to the first one.

\section{DISCUSSION AND CONCLUSIONS}

Statistical characterization regarding attitudes toward building materials and homes was conducted by this study for the first time and provided a superior description of the current situation. This study facilitated linking and comparisons. In the following paragraph, we summarize the results and gather clues related to the attitude toward CSEB architecture in Auroville.

First, the semantic differential method of the questionnaire detected, on average, a positive attitude toward CSEB architecture. This, at a minimum, refutes the notion of negative 
attitudes toward CSEB architecture in Auroville. This method could be tested on other earth-based building techniques, such as adobe, cob, wattle and daub, to investigate negative attitudes. However, the limited use of CSEB, despite favorable attitudes toward this building material, remains problematic. We admit, within the limits of this study, that it is a result of features highlighted in this investigation of the comparison to attitudes toward fired brick architecture.

Second, the distribution of attitudes toward CSEB homes was not normal, unlike the distribution of attitudes toward fired brick homes. This latter feature may serve as a success index of CSEB revalorization projects. To judge the success of a revalorization project of CSEB architecture, proponents of CSEB architecture will reap attitudes and compare them to a normal distribution; if the distribution is normal they are on the right path; if not, more effort is needed for the success of the project. In the case of Auroville, it seems clear that more efforts are needed to encourage the use of CSEB.

Overall, there was no difference between attitudes toward CSEB homes, attitudes toward fired brick homes and attitudes toward homes constructed with other building materials. In Auroville, attitudes toward CSEB homes were neither inferior nor superior to attitudes toward homes constructed with other building materials; they were equivalent. This cannot be seen as a negative factor and leads us to state, for this moment at least, that one cannot discuss negative attitudes toward earthen architecture considering CSEB housing in Auroville. This is supportive, but it is unknown if this is due to AVEI efforts; comparative studies between attitudes toward other building materials could provide more information regarding this issue.

If studies can confirm that attitudes toward a home are slightly favorable regardless of the building material, then the claim of changing attitudes toward CSEB through CSEB housing is improper. However, this does not infer that one would stop CSEB housing. This latter action remains necessary in the context of ecological alternatives although it is not involved in changing attitudes toward CSEB, for which other methods must be found.

Conversely, attitudes toward CSEB are favorable, which is positive, and attitudes are more favorable than those toward fired brick. We emphasize this last point, which is very encouraging compared to what inspired the New Gourna experiment, where the population seemed unfavorable toward the earth-based building material. We desire to travel to New Gourna for a closer study using identical methods for a more reliable comparison.

Third, the comparison of attitudes demonstrates that attitudes toward CSEB homes were equivalent to attitudes toward CSEB building material. This was not the case of attitudes toward fired brick homes, which differed from attitudes toward fired brick. As for the normal distribution, the distinction between attitudes toward the building material and attitudes toward homes was an index of a culmination of a CSEB revalorization project. This is true when we consider fired brick architecture as a reference. Future studies will test this equivalent relationship among attitudes toward other building materials. If the difference between attitudes toward building material and homes is confirmed, the difference between attitudes is an element sought by the population. In this case, equivalence between attitudes toward building material and homes is a negative point of the attitudes toward CSEB architecture.

The correlation coefficient demonstrated a strong positive connection between attitudes toward CSEB homes and CSEB. The connection between the attitudes toward fired brick homes and attitudes toward fired brick was also positive but smaller. When proponents of CSEB architecture would prefer to use fired brick architecture as a model, its coefficient may help in the assessment of the success of CSEB revalorization projects. 
Admittedly, this latter result opens a wide field of research for linking the use (broad/limited) and the correlation (strong/weak) between attitudes toward building materials and buildings. This field could be enhanced by studies similar to this one which consider other materials, such as wood, stone, concrete and steel, and buildings constructed with these building materials. To further analyze attitudes toward earthen architecture, studies should consider other earth-based building techniques such as rammed earth, adobe and cob, and compare them with other types of architecture. We are referring to numerous past and ongoing revalorization projects worldwide. These studies fit the architectural psychology field well. In addition, the limited use of environmentally friendly building materials raises a very relevant issue that future studies should analyze because anthropogenic activity has a significant impact on global ecology.

This research did not analyze if the observed attitudes in Auroville were the result of AVEI efforts. Studies need to be broadened to determine the evolution of attitudes toward CSEB architecture based on the efforts of the proponent of earthen architecture over time. It is also necessary to determine the characteristics of the proper attitudes toward the CSEB linked to its wider use. However, the favorable attitudes noted in this study are good news for proponents of CSEB architecture. This leads us to believe that the Auroville experiment is superior compared to the study being conducted in New Gourna.

Using the semantic differential, this study clarified attitudes toward CSEB architecture. The statistical method allowed comparison and linking. This approach is a promising evaluating method to analyze attitudes toward earthen architecture. The approach demonstrated that there were no immediately readable negative attitudes toward earthen architecture. In addition, the approach allowed us to obtain indicators that may be used to assess situations and facilitate monitoring revalorization projects over time and make decisions regarding the culmination of those efforts. This approach has also opened up a research field regarding the relationship between attitudes toward building materials and buildings that appear to incur problems regarding use and bonding strength. Future research should, through comparison, offer more tangible persuasion methods to promote the use of this environmentally friendly material in the building industry.

\section{ACKNOWLEDGEMENTS}

I thank the team from the Auroville Earth Institute who greatly helped me to achieve this work. Special thanks to Mr. S. Maini for his valuable encouragement. I also thank Mr. R. Bensalem for his guidance. I thank the residents of Auroville who helped me to conduct this research. I thank the officials of the University of Laghouat. Finally, I thank all my colleagues at AVEI, the University of Laghouat and the Polytechnic School of Architecture and Urbanism of Algiers who played a direct or indirect role in publishing this work.

This study was supported by the Ministère de l'Enseignement Supérieur et de la Recherche Scientifique in Algeria 174/PNE 2014.

\section{REFERENCES}

[1] Steg, L., Van Den Berg, A.E. \& de Groot, J.I.M., Environmental Psychology: An Introduction. BPS Blackwell: Oxford, pp. 2-11, 2013.

[2] Hall, M.R., Lindsay, R. \& Krayenhoff, M., Modern Earth Buildings Materials, Engineering, Construction and Applications. Woodhead: Oxford, Cambridge, Philadelphia \& New Delhi, p. 5, 2012.

[3] Minke, G., Building with Earth, Design and Technology of a Sustainable Architecture. Birkhäuser: Basel, 2006. 
[4] World Monument Fund, Online. https://www.wmf.org/content/hassan-fathys-newgourna-past-present-future/. Accessed on: 13 Mar. 2016.

[5] World Monuments Fund. New Gourna Village; Conservation and Community, WMF: New York, 2011.

[6] Fathy, H., Construire avec le peuple. Sindbad: Paris, 1970.

[7] Auroville Earth Institute, Online. http://www.earth-auroville.com/about_us_en.php/. Accessed on: 13 Mar. 2016.

[8] Field, A., Discovering Statistics Using SPSS. SAGE: Singapore, London, California \& New Delhi, p.12, p 631 \& p.209, 2009.

[9] Osgood, C.E., Suci, G.J. \& Tannenbaum, P.H., The Measurement of Meaning. University of Illinois Press: Urbana, Chicago \& London, 1967.

[10] Stuart, O. \& Wesley, S.P., Attitudes and Opinions. Mahwah Lawrence Erlbaum Associates: New Jersey \& London, p. 55 \& p. 98, 2005.

[11] Maini, S. \& Thautam, V., Embodied Energy of Various Materials and Technologies. AVEI: Auroville, p. 1, 2013. 